\title{
A Case of Synchronous Squamous Cell Carcinoma in the Esophagus and Stomach
}

\author{
Sun Min Lim*, Eun Suk Jung*, Sung Kwan Shin*, Hyun Soo Chung*, Hyung II Kim ${ }^{\dagger}$, Do Whan Kim , and Byoung Chul \\ Cho* \\ Departments of "Internal Medicine, ${ }^{\dagger}$ General Surgery, and ${ }^{\ddagger}$ Pathology, Severance Hospital, Yonsei University Health System, Seoul, Korea
}

Synchronous esophageal and gastric cancers with the pathologic features of a squamous cell carcinoma are extremely rare. A 57-year-old male visited our hospital with a history of hematemesis and was diagnosed with a synchronous cancer. He underwent a staging work-up, and the resectable lesion in the stomach was operated on following radiologic and endoscopic evaluations. The pathologic examination revealed a synchronous cancer consisting of squamous cell carcinoma in the distal esophagus and the cardia of the stomach. We report a case of a synchronous cancer that was successfully treated by surgical resection followed by concurrent chemoradiotherapy. We also discuss the hypothesis regarding the origin and presentation of the synchronous cancer and highlight the importance of careful surveillance by physicians at the time of diagnosis. (Gut Liver 2012;6:118-121)

Key Words: Synchronous; Esophageal neoplasms; Stomach neoplasms

\section{INTRODUCTION}

A synchronous cancer of squamous cell origin found in the esophagus and stomach is very rare among gastrointestinal cancers. Squamous cell carcinomas take up 38\% of all esophageal cancers, and it is common in esophagus, but not in stomach. ${ }^{1,2}$ Less than 100 cases were reported until now. ${ }^{3}$ A synchronous presentation of squamous cell carcinoma in the esophagus and stomach is so rare that it has not been reported in Korea, yet. Therefore, making an accurate diagnosis is crucial in order to plan treatment for the synchronous cancer. We have experienced a squamous cell carcinoma of esophagus and stomach and therein report this case to demonstrate that the cancer can be treated through accurate diagnosis, effective surgery and combination of chemoradiation therapy.

\section{CASE REPORT}

A 57 year old male was admitted to the Department of Oncology complaining of dyspepsia for 2 months and sudden onset of hematemesis. He underwent endoscopy and computed tomography (CT) and was diagnosed with esophageal cancer and stomach cancer. He had a history of complete atrioventricular block and had a pacemaker implemented in 1992. He had diabetes mellitus and his social history was significant for drinking a bottle of alcohol daily and smoking one pack of cigarettes for 30 years. He had no significant family history.

He was chronic ill-looking, and alert. His blood pressure was 120/80 mm Hg, pulse 60/min, respiration 20/min, body temperature $36.5^{\circ} \mathrm{C}$. His skin was dry and warm, with pale icterus and dry tongue. His lungs were clear to auscultation and his heart was regular without murmur or rubs. His bowel movement was normal without abdominal pain or tenderness. His liver and spleen were not palpable. The complete blood count

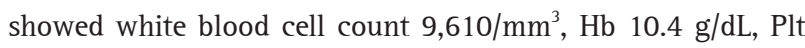
$284 \times 10^{3} / \mathrm{mm}^{3}$. His blood chemistry was normal, with tumor markers carcinoembryonic antigen (CEA) $2.22 \mathrm{ng} / \mathrm{mL}$ and squamous cell carcinoma antigen (SCC Ag) $2.2 \mu \mathrm{g} / \mathrm{L}$. The chest Xray and simple abdomen showed no abnormality. On CT, there was an ulcerofungating mass from the pylorus of the stomach to lower esophagus. The stomach lesion was abutting the tail of the pancreas and the diaphragm on CT (Fig. 1). The positron emission tomography-computed tomography (PET-CT) showed no distant metastasis other than suspicious cancerous lesion in stomach and esophagus. He then underwent upper gastrointestinal endoscopy and endoscopic ultrasound with biopsy. The endoscopic finding revealed an irregular shaped lesion with

\footnotetext{
Correspondence to: Byoung Chul Cho

Department of Internal Medicine, Yonsei University College of Medicine, 250 Seongsanno, Seodaemun-gu, Seoul 120-752, Korea

Tel: +82-2-2228-8100, Fax: +82-2-312-4227, E-mail: cbc1971@yuhs.ac

Received on July 8, 2010. Accepted on September 13, 2010.

pISSN 1976-2283 eISSN 2005-1212 http://dx.doi.org/10.5009/gnl.2012.6.1.118

(a) This is an Open Access article distributed under the terms of the Creative Commons Attribution Non-Commercial License (http://creativecommons.org/licenses/by-nc/3.0) which permits unrestricted non-commercial use, distribution, and reproduction in any medium, provided the original work is properly cited.
} 

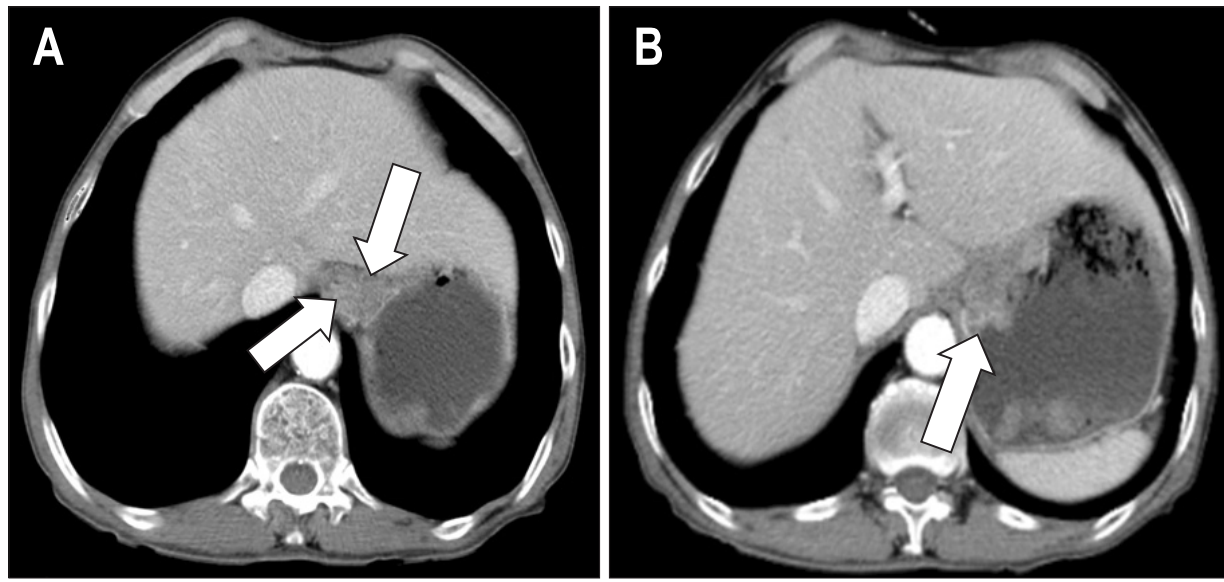

Fig. 1. (A) An abdominopelvic computed tomography shows an ulcerofungating mass at the gastric fundus (B) that extended to the esophagogastric junction and distal esophagus with serosal exposure.
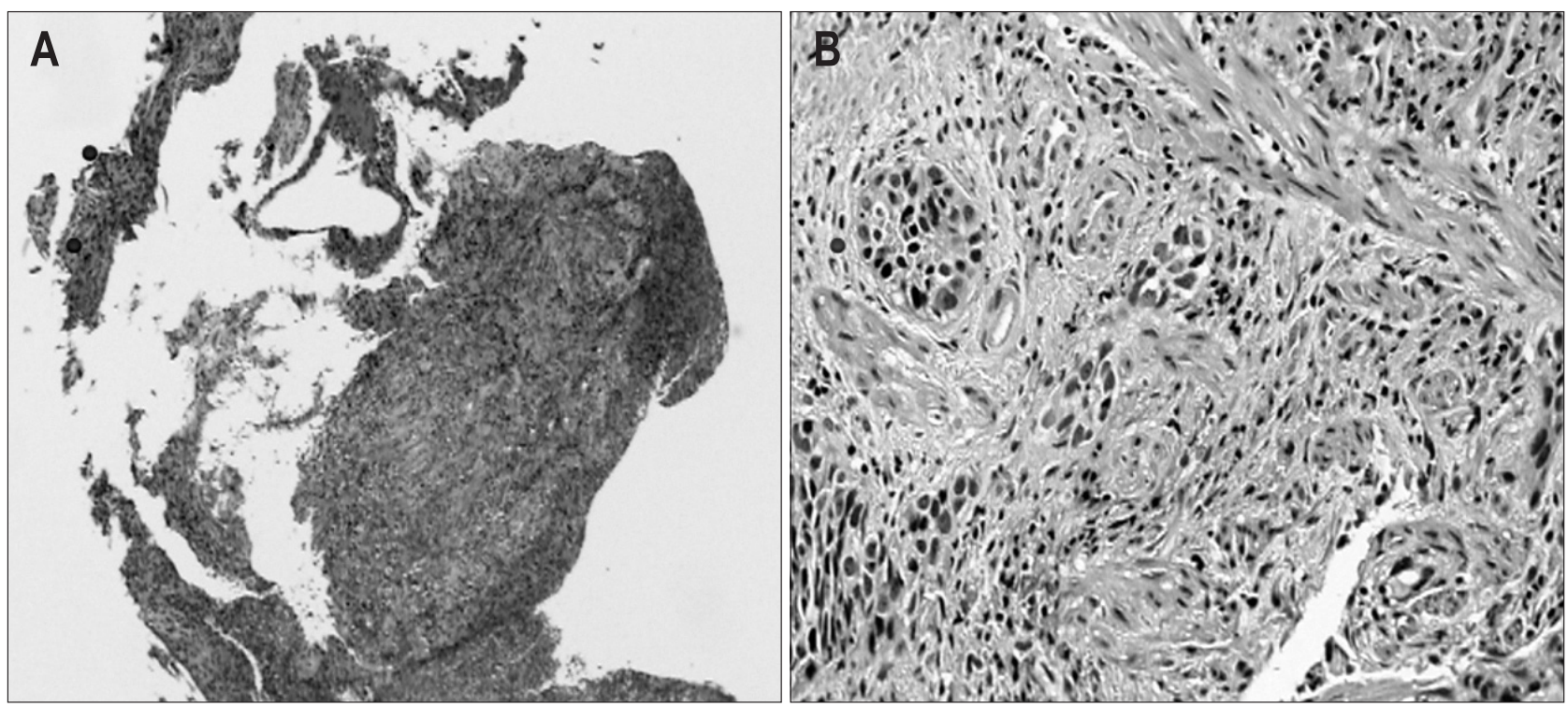

Fig. 2. (A) Microscopic findings of invasive squamous cell carcinoma obtained from the esophagus (H\&E stain, $\times 40$ ). (B) The lesion is poorly differentiated (H\&E stain, $\times 200)$.

decreased vascular marking from 31 to $39 \mathrm{~cm}$ from upper incisor. The main cancer lesion in the esophagus was $35 \mathrm{~cm}$ from UI with serosa invasion and local lymph node metastasis. It was poorly-differentiated squamous cell carcinoma (Fig. 2). The stomach lesion was Bormann III shaped, moderately-differentiated squamous cell carcinoma, with serosa exposure and local lymph node invasion by $9 \mathrm{~mm}$ (Fig. 3).

According to above findings, the stomach lesion was resectable and he underwent total gastrectomy and esophagoduodenostomy. ${ }^{4}$ The operative findings showed a $6 \times 6 \mathrm{~cm}$ sizedulcerofungating mass in the lesser curvature of the stomach that invaded soft tissue of the pancreas (Fig. 4). There was no distant metastasis to liver or rectum. Postoperative findings demonstrated a squamous cell carcinoma of the stomach, pT4N2M0 with serosa invasion, 4 out of 41 local lymph nodes metastasis with perineurovascular invasion. The pathologic finding showed that the proximal resection margin of the gastric lesion was negative. This suggests the squamous cell carcinoma of the stomach was not a direct extension from squamous cell carcinoma of esophagus. They were indeed two separate cancers with different pathology.

The patient was in good condition after the surgery, and underwent combination chemoradiotherapy (5-Fluorouracil/ Cisplatin: 5FU $1 \mathrm{~g} / \mathrm{m}^{2}$ per day on the first 4 days of weeks 1,5 , 8 , and 11 th weeks, Cisplatin $75 \mathrm{mg} / \mathrm{m}^{2}$ on first days of $1,5,8$, 11th weeks, Radiotherapy 2.0 Gy for 5 days a week). He is now in complete remission and regularly followed up in outpatient clinic.

\section{DISCUSSION}

There have been a few reports on the double primary cancers consisting of esophageal squamous cell carcinomas and gastric adenocarcinomas, but squamous cell carcinoma of stomach is a rare finding as described in this report. Recently, there has been increasing incidence of esophageal cancers associated with Bar- 

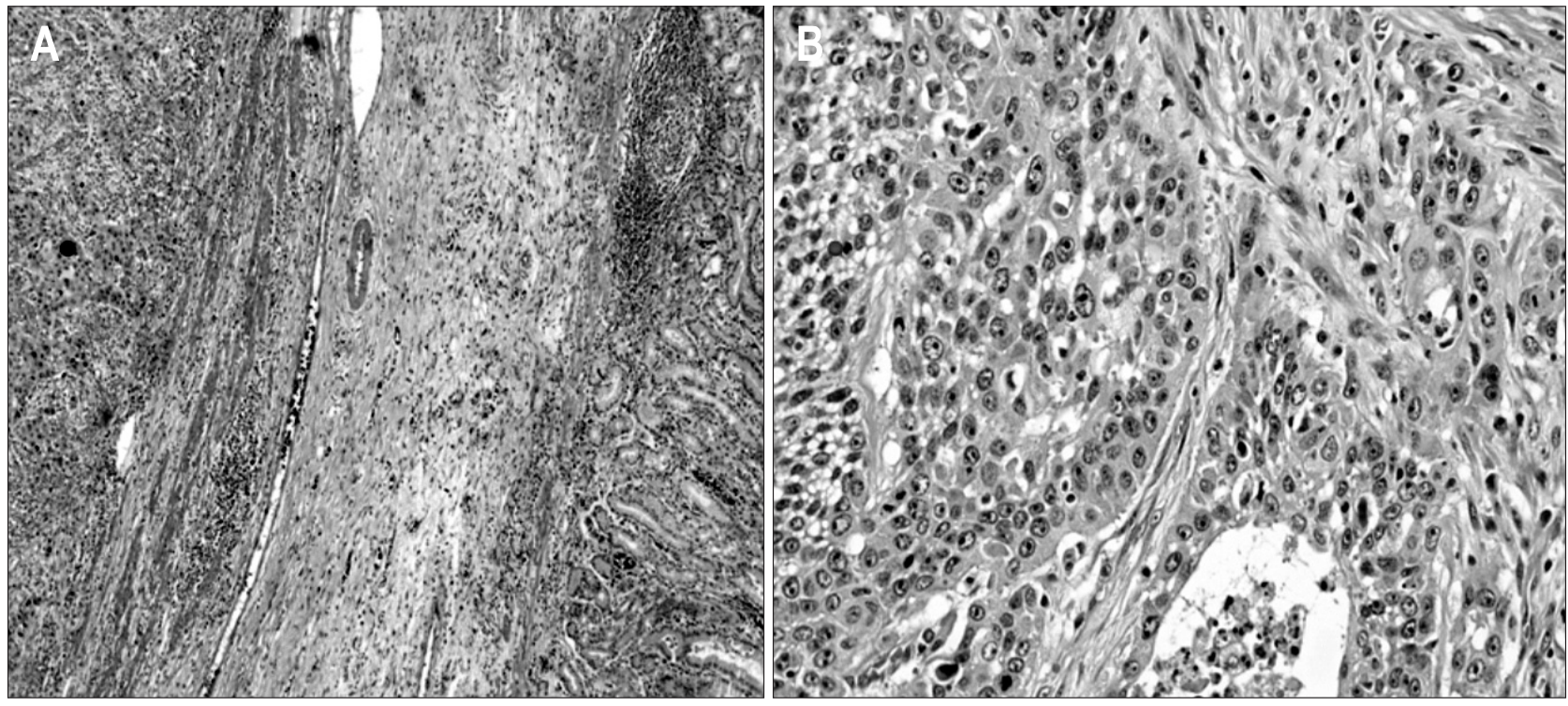

Fig. 3. (A) The cancer mucosa compared to the normal mucosa obtained from the lesser curvature of the upper body of the stomach (H\&E stain, $\times 40$ ). (B) The invasive squamous cell carcinoma of the stomach is moderately differentiated (H\&E stain, $\times 200$ ).

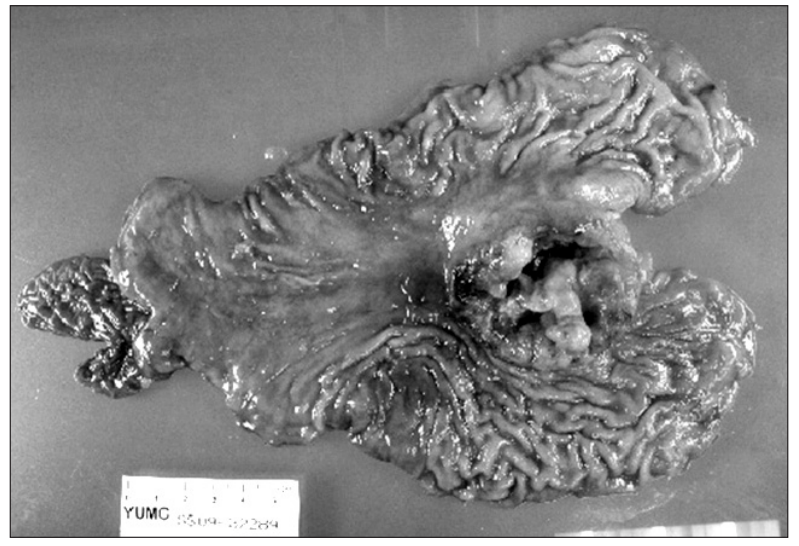

Fig. 4. A gross specimen from the stomach after total gastrectomy, pT4N2M0. There is an ulcerofungating mass measuring $6 \times 6 \mathrm{~cm}$ in the lesser curvature of the cardia. It is located $1.3 \mathrm{~cm}$ from the proximal resection margin and $12.5 \mathrm{~cm}$ from the distal resection margin. Both the proximal and distal resection margins are shown to be free of carcinoma (a safety margin of $1.3 \mathrm{~cm}$ and a safety margin of 12.5 $\mathrm{cm}$, respectively).

rett's esophagus. Adenocarcinomas increased by six-fold from 1975 to 2001, while 97 percent of adenocarcinoma arising from esophagogastric junction is associated with Barrett's esophagus. $^{5,6}$ The prevalence of squamous cell carcinoma is on the decline, but still common in Asia in association with smoking and alcohol consumption., ${ }^{7,8}$

The metastasis of esophageal cancer occurs commonly through lymphatic systems, and intramural metastasis plays an important role in tumor distribution. Intramural metastasis is known to have a poor prognosis. Among 1,259 patients who received surgical resection of esophageal cancers, 93 (7.4\%) had intramural metastasis, and 13 (1.0\%) had gastric metastasis among them. These metastatic lesions looked similar to gastric submucosal tumor, which suggested that metastasis occurred through lymphatic systems. ${ }^{9}$

To diagnosis a synchronous cancer, three conditions should be satisfied. First of all, cancer lesions should be located apart from each other, and should not be contiguous. Secondly, they must be pathologically different. Thirdly, both lesions should have mucosal lesions. In our case, the postoperative pathologic findings showed that the proximal resection margin of the gastric lesion was negative, which implies that two lesions were located separately. That is, the cancer originates from two lesions; one from the lower esophagus and the other from the gastric fundus. Moreover, the fact that the level of differentiation was different in two lesions suggests that they arise from different origins. Valduga et al. ${ }^{10}$ reported a synchronous cancer with undifferentiated squamous cell carcinoma of stomach and well-differentiated squamous cell carcinoma of esophagus. In this regard, the main lesion of the synchronous cancer occurred from the fundus of the stomach reaching the esophagogastric junction, and the lower esophagus.

Squamous cell carcinoma mainly occurs in the mid to lower esophagus, and it is not uncommon to have other accompanying cancerous lesions. Suzuki et al. ${ }^{11}$ reported that the most common lesion is the stomach (59.6\%), and then colon and rectum (12.3\%) in the order of frequency. Also, it has been reported that the mortality from the accompanying cancerous lesions is higher than the mortality from the esophageal cancer itself. ${ }^{12}$ Therefore, it is important to consider the possibility of other existing cancers other than the esophagus. Since the only curative treatment of esophageal cancer or gastric fundus cancer is surgical resection, it is imperative that we examine the possible metastatic lesions thoroughly before deciding the operation.

Until now, the standard therapy of advanced esophageal can- 
cer is combined modality therapy: 50 Gy in 25 fractions over 5 weeks, plus cisplatin intravenously on the first day of weeks 1,5 , 8 , and 11 , and fluorouracil, $1 \mathrm{~g} / \mathrm{m}^{2}$ per day by continuous infusion on the first 4 days of weeks $1,5,8$, and 11 . In a randomized trial, combined therapy increased the survival of patients who have squamous cell or adenocarcinoma of the esophagus, compared with radiotherapy alone. ${ }^{13,14}$

In this case, we demonstrated the synchronous cancer of squamous cell origin in the esophagus and stomach. Esophageal cancer tends to spread axially, up and down the length of the organ and to regional lymphatics, producing morbidity and mortality. However, another cancer can be discovered synchronously. Therefore, when making a diagnosis, staging a cancer and evaluating treatment response, we should be aware that there may be potential cancer lesions other than the esophagus. Through prudent diagnosis and treatment plan, complete resection of the tumor burden and chemoradiation therapy for the unresectable lesion will lead to improvement in patient survival.

\section{CONFLICTS OF INTEREST}

No potential conflict of interest relevant to this article was reported.

\section{REFERENCES}

1. Ishihara R, Tanaka H, lishi H, et al. Long-term outcome of esophageal mucosal squamous cell carcinoma without lymphovascular involvement after endoscopic resection. Cancer 2008;112:21662172.

2. Trivers KF, Sabatino SA, Stewart SL. Trends in esophageal cancer incidence by histology, United States, 1998-2003. Int J Cancer 2008;123:1422-1428.

3. Callacondo D, Ganoza-Salas A, Anicama-Lima W, QuispeMauricio A, Longacre TA. Primary squamous cell carcinoma of the stomach with paraneoplastic leukocytosis: a case report and review of literature. Hum Pathol 2009;40:1494-1498.
4. Berrisford RG, Wong WL, Day D, et al. The decision to operate: role of integrated computed tomography positron emission tomography in staging oesophageal and oesophagogastric junction cancer by the multidisciplinary team. Eur J Cardiothorac Surg 2008;33:1112-1116.

5. von Rahden BH, Stein HJ, Siewert JR. Surgical management of esophagogastric junction tumors. World J Gastroenterol 2006;12:6608-6613.

6. Stein HJ, Feith M, Bruecher BL, et al. Early esophageal cancer: pattern of lymphatic spread and prognostic factors for long-term survival after surgical resection. Ann Surg 2005;242:566-573.

7. Steevens J, Schouten LJ, Goldbohm RA, van den Brandt PA. Alcohol consumption, cigarette smoking and risk of subtypes of oesophageal and gastric cancer: a prospective cohort study. Gut 2010;59:39-48.

8. Kuwano H, Nakajima M, Miyazaki T, Kato H. Distinctive clinicopathological characteristics in esophageal squamous cell carcinoma. Ann Thorac Cardiovasc Surg 2003;9:6-13.

9. Takubo K. Epithelial dysplasia and squamous cell carcinoma: pathology of the esophagus. Tokyo: EDUCA Inc., 2000:131-168.

10. Valduga P, Fiamingo P, Prezzi C, Marcucci S, Eccher C. Synchronous gastric and oesophageal cancer: a case report. Chir Ital 2008;60:449-452.

11. Suzuki S, Nishimaki T, Suzuki T, et al. Outcomes of simultaneous resection of synchronous esophageal and extraesophageal carcinomas. J Am Coll Surg 2002;195:23-29.

12. Sato Y, Motoyama S, Maruyama K, Okuyama M, Ogawa J. A second malignancy is the major cause of death among thoracic squamous cell esophageal cancer patients negative for lymph node involvement. J Am Coll Surg 2005;201:188-193.

13. Cooper JS, Guo MD, Herskovic A, et al. Chemoradiotherapy of locally advanced esophageal cancer: long-term follow-up of a prospective randomized trial (RTOG 85-01). Radiation Therapy Oncology Group. JAMA 1999;281:1623-1627.

14. Udagawa H. Chemoradiotherapy: its effectiveness, toxicity, and perspective in the treatment of esophageal cancer. Ann Thorac Cardiovasc Surg 2009;15:359-361. 